\title{
IMMOBILIZED SACCHAROMYCES CEREVISIAE AS A POTENTIAL AFLATOXIN DECONTAMINATING AGENT IN PISTACHIO NUTS
}

\author{
S. Rahaie ${ }^{1}$, Z. Emam-Djomeh ${ }^{* 1}$, S. H. Razavi ${ }^{1}$, M. Mazaheri ${ }^{2}$ \\ ${ }^{1}$ Department of Food Science, Technology \& Engineering, Faculty of Biosystems Engineering, University of Tehran, 31587- \\ 11167 Karaj, Iran; ${ }^{2}$ Iran Industrial Research and Standards Institution, Karaj, Iran.
}

Submitted: September 02, 2008; Returned to authors for corrections: March 03, 2009; Approved: August $22,2009$.

\begin{abstract}
In this study, we investigated the binding ability of Saccharomayces cerevisiae to aflatoxin in pistachio nuts. The obtained results indicate that $S$. cerevisiae has an aflatoxin surface binding ability of $40 \%$ and $70 \%$ (with initial aflatoxin concentrations of 10 and $20 \mathrm{ppb}$ ) in the exponential phase. Acid treatments increase this ability to approximately $60 \%$ and $73 \%$ for the two concentrations of aflatoxin, respectively. Heat treatments also enhance surface binding to $55 \%$ and $75 \%$, respectively. Binding appears to be a physical phenomenon that saturates within the first 2-3 hours of the process. The obtained results indicate that yeast immobilization for toxin reduction on aflatoxin-contaminated pistachios had no effect on qualitative characteristics, such as color, texture, and peroxide value. Yeast cells, viable or nonviable, are effective for aflatoxin binding, and this property could lead to a promising solution to aflatoxin contamination in high-risk foods.
\end{abstract}

Key words: Aflatoxin, Pistachio nut, Saccharomayces cerevisiae, Surface binding

\section{INTRODUCTION}

Several Aspergillus species produce mycotoxins that may be toxic, mutagenic, or carcinogenic. Chemically, aflatoxins are defined as a series of 18 known bisulfuran polycyclic compounds that fluoresce strongly in ultraviolet light. Other Aspergillus species known to produce aflatoxins are $A$. parasiticus and A.nomius. In general, A. flavus produces aflatoxins $\mathrm{B}_{1}$ and $\mathrm{B}_{2}$, while $A$. parasiticus produces $\mathrm{B}_{1}, \mathrm{~B}_{2}, \mathrm{G}_{1}$, and $\mathrm{G}_{2}$. The commodities with the highest risk of aflatoxin contamination include corn, peanut, cottonseed, Brazil nut, pistachio nut, fig, spice, and copra (8). Aflatoxins are heatstable and are hard to transform into non-toxic products (12).
Intake of aflatoxin is directly associated with human liver cancer, and has also been confirmed to induce a high incidence of mutation in the p53 tumor repressor gene and K-ras and $\mathrm{H}$ ras proto-oncogenes (6).

Pre-harvest impediment of aflatoxin (AF) formation is difficult; therefore, aflatoxins in foods and feeds are considered a continuous risk. Nowadays, aflatoxin as a recognized potent carcinogen has become a health hazard for worldwide pistachio consumers (10). The pistachio nut is the second largest nonpetroleum export product, and has a significant role in the development of the national economy and the agro-food industry of Iran (16). Pistachio nuts are a rich source of fat and contain fatty acids, such as oleic, linoleic, and linolenic acid, 
which are essential for the human diet (2). Presently, the worldwide limits for aflatoxin B1 (AFB1) and total aflatoxin (AFT) are $10 \mathrm{ppb}$ and $15 \mathrm{ppb}$, respectively. According to a report published by the Iranian Ministry of Health, of 7926 pistachio samples analyzed during March 2001-March 2002, data indicated that 761 samples contained $\mathrm{AFB}_{1}$ concentrations higher than $10 \mu \mathrm{g} / \mathrm{kg}$ (8). Abdulkadar, Al-Ali, and Al-Jedah (2000) reported an AF incidence of $37 \%$ with total AF levels in the range of $0.53-289 \mu \mathrm{g} / \mathrm{kg}$. It is interesting that in all the investigated pistachios samples, only aflatoxins $B_{1}$ and $B_{2}$ were detected, whereas aflatoxins $G_{1}$ and $G_{2}$ were detected in only a few pistachios (17). This might be due to the invasion of nuts by $A$. flavus rather than $A$. parasiticus.

Pistachios without shells were highly contaminated with aflatoxin. The reasons for this might be pre-harvest contamination in the field followed by cross-contamination after de-shelling, poor storage and handling resulting in positive conditions for mould growth and toxin production (1).

Several methods for decontamination and post-harvest control have been reported. Other decontamination approaches include food and feed processing, such as thermal inactivation, irradiation, solvent extraction, mechanical separation, density segregation, and reduction in bioavailable aflatoxin by selective chemisorptions. Although such treatments almost completely reduce mycotoxin concentrations, these chemicals also reduce nutrient concentrations (4, 9, 15). Evidently, the best decontaminant should be detoxification by biodegradation, which might remove mycotoxins under mild conditions. Among the different decontaminating microorganisms available, we selected Saccharomyces cerevisiae, a unique yeast, widely used in food fermentation and preservation ( 7 , 19), as a potentially effective microorganism for the removal of aflatoxin in pistachios. Cell immobilization in food science is an attractive and rapidly-expanding research area because of its technical and economical advantages compared to a free cell system; however, for applications in the food industry, immobilization supports should satisfy additional fundamentals, such as food grade purity, cost effectiveness, availability, and positive contribution to the sensory characteristics of the original product (13).

The objective of the present study is to evaluate the biological decontamination of aflatoxin using immobilized $S$. cerevisiae.

\section{MATERIALS AND METHOD}

\section{Chemicals and yeast}

Aflatoxin $\mathrm{B}_{1}$ solution was purchased from Sigma Co. (St. Louis, MO, USA). Methanol, chloroform, acetone, n-hexane, acetonitrile, phosphate-buffered saline (PBS), and potassium bromide were supplied by Merck Co (Stutgart, Germany). Sodium alginate was obtained from BDH Co. (Dubai, UAE) and calcium chloride from Scharlau Co. (Germany). Saccharomyces cerevisiae (ATCC 9763) was obtained from a Persian-type culture collection in Iran.

\section{Sample preparation}

Akbari is the major pistachio cultivar grown in Iran; therefore, this cultivar was selected in this study. A freshlyharvested pistachio variety was purchased from Kerman, Iran. Pistachios were then subjected to de-hulling, trash and blank separation, unpeeled and unripe pistachio separation, washing, and sorting (to separate nuts from non-split ones). In order to achieve samples with lower moisture content, an identified mass of pistachio was dried by an oven equipped with a ventilator at $50{ }^{\circ} \mathrm{C}$. Finally, the samples were kept at $-20{ }^{\circ} \mathrm{C}$ in a freezer until the start of the experiments. $10 \mathrm{ppb}$ and $20 \mathrm{ppb}$ aflatoxin $\mathrm{B}_{1}$ solutions were prepared by adding phosphatebuffered saline (PBS) to pure aflatoxin. De-hulled pistachios were immersed in these solutions for 24 hours in order to contaminate them.

\section{Culture preparation}

A strain grown in yeast mold broth (YM Broth) tubes for 48 hours at $25{ }^{\circ} \mathrm{C}$ was used as the inocula. Erlenmeyer flasks containing $100 \mathrm{~mL}$ of YM Broth were inoculated with the desired culture at a concentration of $10^{2}$ cells $/ \mathrm{mL}$ and incubated 
at $25{ }^{\circ} \mathrm{C}$ until the cells reached an $\mathrm{OD}_{600}$ of $1.8-2 \times 10^{10}$ cells/mL. Cells harvested at the required OD were centrifuged at $5000 \times \mathrm{g}$ for $10 \mathrm{~min}$, washed twice with phosphate buffered saline (PBS, $\mathrm{pH}=6.0$ ), and spun again at $5000 \times \mathrm{g}$ for $10 \mathrm{~min}$ after each wash. Heat treated (autoclaved in $10 \mathrm{~mL}$ PBS at 120 ${ }^{\circ} \mathrm{C}$ for $20 \mathrm{~min}$ ) and acid treated (incubated at $25^{\circ} \mathrm{C}$ in $10 \mathrm{~mL}$ $2 \mathrm{M} \mathrm{HCl}$ for $90 \mathrm{~min}$ with mild shaking) samples were washed twice with $4 \mathrm{~mL}$ PBS and centrifuged at $5000 \times \mathrm{g}$ for $10 \mathrm{~min}$ prior to use $(2,8)$.

\section{Cell immobilization}

Alginate solutions in a concentration range of $0.5-10 \%$ can be used for cell immobilization. Sodium alginate solution (3\%) was prepared by dissolving sodium alginate in $100 \mathrm{~mL}$ boiling water and autoclaved at $121{ }^{\circ} \mathrm{C}$ for $15 \mathrm{~min}$. Cells were harvested in every manner of treatment, re-suspended in $2 \mathrm{~mL}$ of saline, and added to sterilize alginate solution. In order to immobilize the cells in alginate, pistachios were dipped in a 0.2 $\mathrm{M} \mathrm{CaCl}_{2}$ solution (13).

\section{Extraction and clean-up procedures for HPLC analysis}

Samples were analyzed using a high performance liquid chromatography (HPLC) method (the AOAC official method 999.7). A ground pistachio sample (50 g) was blended with 2.5 $\mathrm{g} \mathrm{NaCl}$ and a $200 \mathrm{~mL}$ solution of $80 \%$ methanol in water for 5 min. Then the mixture was filtered through Whatman filter paper. After filtration, the extract was diluted with water and filtered through a glass microfiber filter. Aflatest IACs were used to clean-up the samples. A $15 \mathrm{~mL}$ phosphate buffer saline (PBS) was first passed during the IAC. Then, $70 \mathrm{~mL}$ of the filtrate was passed through the IAC at a flow rate of ca.1 drop/s. The column was washed with $15 \mathrm{~mL}$ water and dried by application of vacuum. Finally, AF was eluted with methanol using the subsequent procedure. First, $0.5 \mathrm{~mL}$ of methanol was applied to the column and allowed to pass through by gravity. After $1 \mathrm{~min}$, the second part of the $1 \mathrm{~mL}$ methanol was applied and collected. The eluate was diluted with water and analyzed by $\operatorname{HPLC}(2,8)$.

\section{Determination of aflatoxins by the HPLC method}

Aflatoxins were isocratically separated using HPLC (Waters model 2475, USA), a fluorescence detector, and $50 \mu \mathrm{L}$ of injected sample solution. The mobile phase was deionized water-acetonitrile-methanol (60:20:20, v/v) with the addition of $350 \mu \mathrm{L}$ of $4 \mathrm{M} \mathrm{HNO} 3$ and $12 \mathrm{mg}$ of $\mathrm{KBr}$ at a flow rate of 1 $\mathrm{mL} / \mathrm{min}$. The fluorescence detector was set at an excitation wavelength of $362 \mathrm{~nm}$ and emission wavelength of $450 \mathrm{~nm} \mathrm{(2,}$ 8). Quantification of each toxin was performed by measuring their peak areas and comparing them with their relevant standard calibration curve (retention time $=10.25$ minutes, $0.035 \mathrm{ng}<$ quantification $<0.405 \mathrm{ng}$, standard deviation $= \pm$ $0.001 \mathrm{ng}$ ), Percent binding was determined from the amount of unbound $\mathrm{AFB}_{1}$ remaining on the pistachio after incubation when compared to control (without yeast cells) before coating with alginate:

$\%$ bound $=100[1-$ counts in the sample after coating $/$ counts in control].

\section{Microscopic examinations}

Scanning electron microscopy (SEM) was used to study the morphology of the immobilized $S$. cerevisiae cells in alginate. The alginate was fixed on the pistachio samples. Finally, the samples were dried, coated with gold, and observed with a Philips XL 30 (Netherlands) microscope.

\section{Color evaluation}

Pistachio sample color $\mathrm{L}$, $\mathrm{a}$, and $\mathrm{b}$ values were measured by the Hunter Lab (Konica Minolta, Japan). Pistachio color was measured before and after coating with sodium alginate.

\section{Determination of peroxide value}

The peroxide value of the pistachio samples was measured before and after coating with sodium alginate to determine the peroxide value in fat content. Peroxide value (PV) was determined by the AOCS (1993) methods (3).

\section{Texture study}

Pistachio texture changes were measured by compressing samples with a Testometric (M350-10CT, Rochdale, England). 
The Maximum force $(\mathrm{N})$ required to compress the sample was recorded as the firmness of the pistachio sample. Pre-test speed, test speed, and post-test speed were all set at 10 $\mathrm{mm} / \mathrm{min}$. Triplicates of each treatment were evaluated.

\section{Statistical analysis}

All of the analyses were done in triplicate sets belonging to three different batches. Values are represented as the mean values. Data were analyzed by ANOVA using Minitab 15 and the significance is expressed at a $5 \%$ significance level $(\mathrm{p}<$ $0.05)$.

\section{RESULTS AND DISCUSSIONS}

S. cerevisiae cells were capable of binding large amounts of aflatoxin $\mathrm{B}_{1}$, even at the highest evaluated concentration (20 ppb). Yeast binding ability was largest when located in the exponential phase and under acidic conditions. Results indicate that the binding stage is a rapid process that saturates after 3 hours. Figure 1 indicates Aflatoxin binding at an exponential phase by means of S. cerevisiae ATTC 9763 was immobilized on pistachios with $10 \mathrm{ppb}$ and $20 \mathrm{ppb} \mathrm{AFB}_{1}$. Figure 2 demonstrates that heating, even at $120{ }^{\circ} \mathrm{C}$ for $20 \mathrm{~min}$, could increase yeast binding ability to $55 \%$ and $75 \%$ with primary $\mathrm{AFB}_{1}$ concentrations of 10 and $20 \mathrm{ppb}$, respectively.

Heating may also raise the permeability of the external layer of the cell wall due to the suspension of some of the mannans from the cell surface, leading to the increased availability of the otherwise hidden binding sites. In addition, there will be countless physical-chemical changes taking place in the cell wall during the heat treatment, resulting in more exposed binding sites.

Figure 3 demonstrates the cell treatment under acid conditions could increase the binding ability to $60 \%$ and $73 \%$ for the two investigated concentrations of aflatoxin, respectively. It is possible that the acidic conditions could affect polysaccharides by releasing monomers, which are further fragmented into aldehydes after the breaking down of glycosidic linkages. Moreover, it was shown that increases in $\mathrm{AFB}_{1}$ concentration enhanced the binding ability of yeast cells. In comparison, among the three conditions (Figs. 2 and 3), the binding ability of yeast cells in acid and heat treatments are higher than those in the exponential phase. Furthermore, infrequent acid treatment is better than heat and acts in a similar manner.

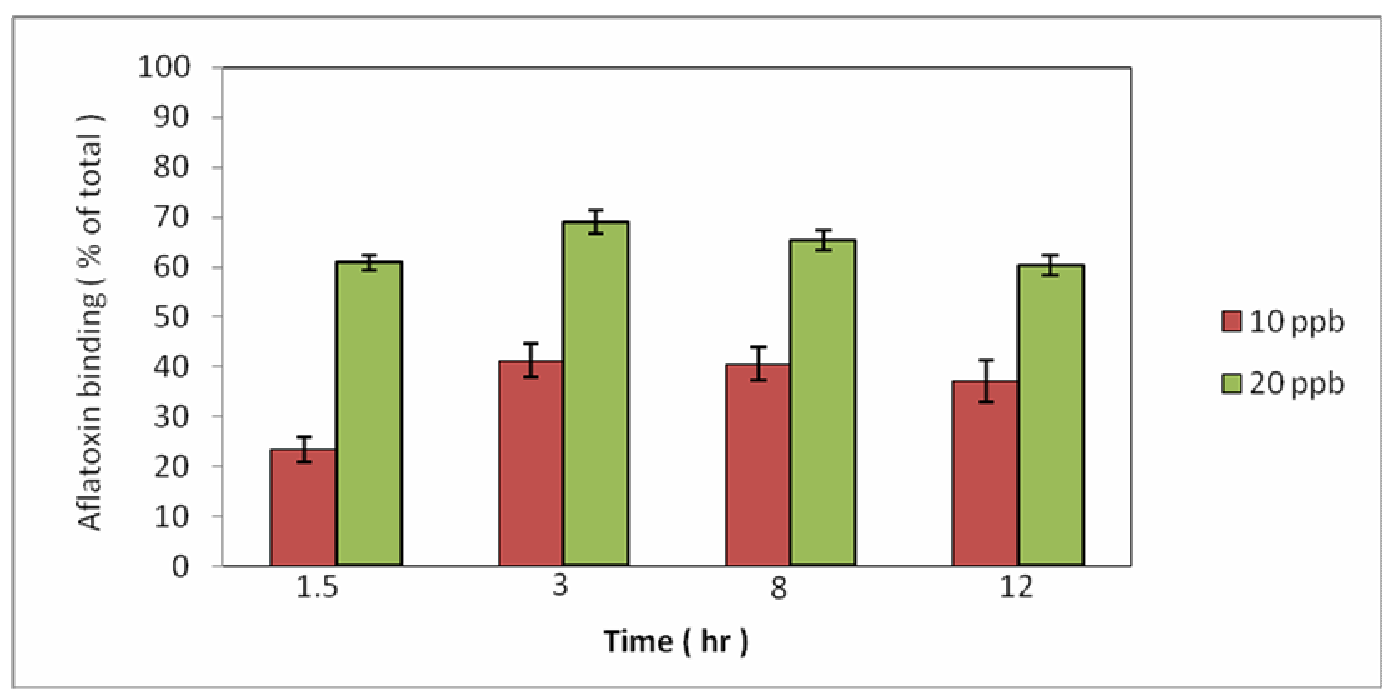

Figure 1. Aflatoxin binding at exponential phase, S. cerevisiae ATTC 9763 was grown at $25{ }^{\circ} \mathrm{C}$ and cells harvested at middle log phase were immobilized on pistachio whit $10 \mathrm{ppb}$ and $20 \mathrm{ppb}$ aflatoxin $\mathrm{B} 1$ : for $12 \mathrm{hr}$ at $25^{\circ} \mathrm{C}$ 
Rahaie, S. et al.

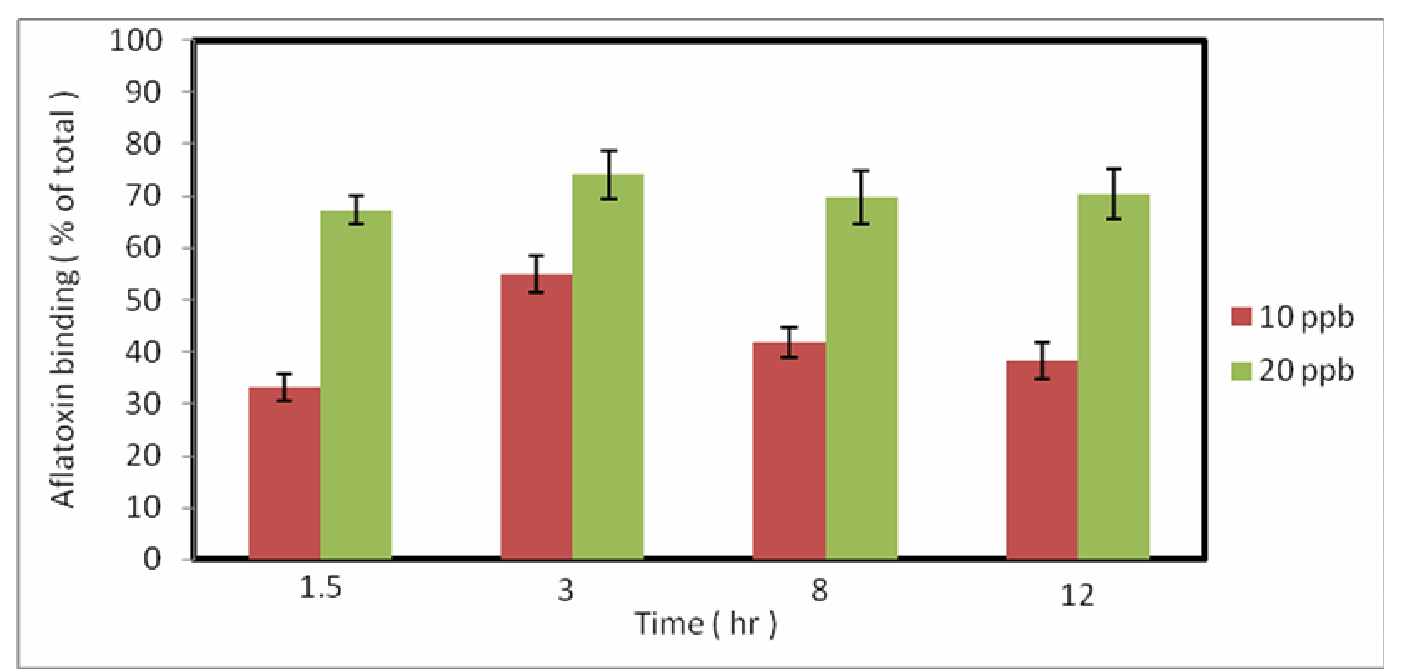

Figure 2. Aflatoxin binding at heat condition, S. cerevisiae ATTC 9763 was grown at $25{ }^{0} \mathrm{C}$ and cells treated whit Autoclave (at $121{ }^{\circ} \mathrm{C}$, for $20 \mathrm{~min}$ ) were immobilized on pistachio whit10 ppb and $20 \mathrm{ppb}$ aflatoxin $\mathrm{B} 1$ : for $12 \mathrm{hr}$ at $25^{\circ} \mathrm{C}$

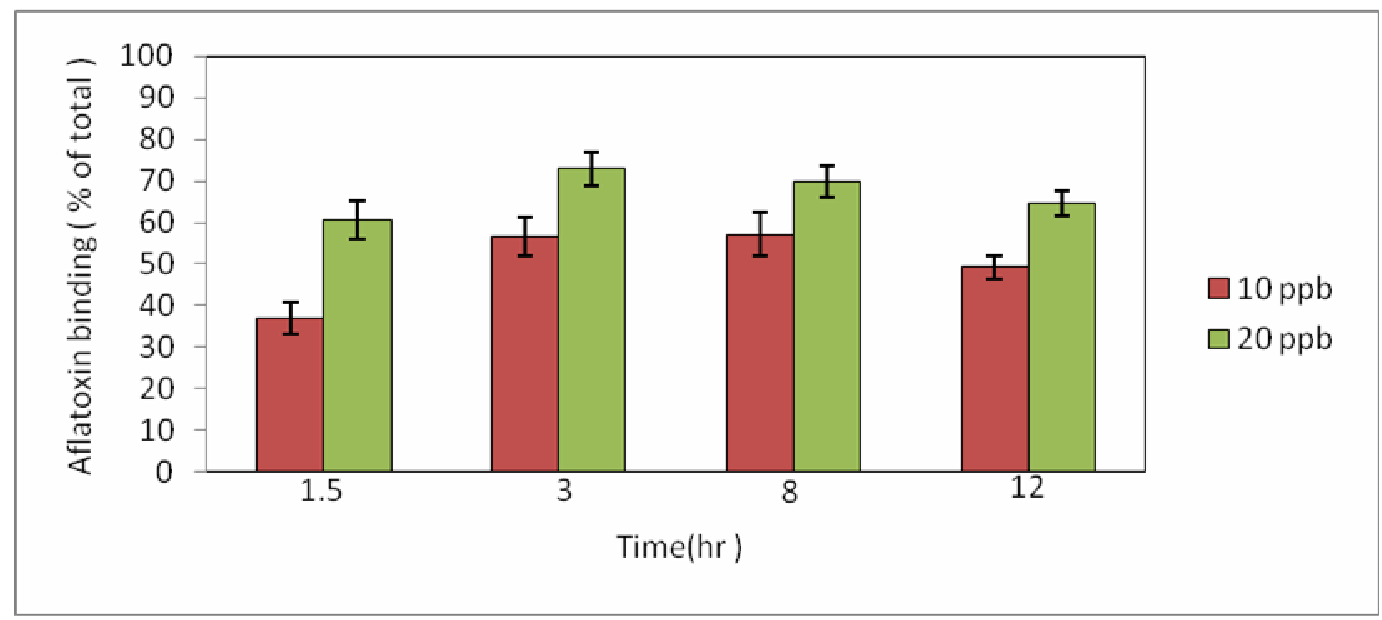

Figure 3. Aflatoxin binding at acidic condition, S. cerevisiae ATTC 9763 was grown at $25{ }^{0} \mathrm{C}$ and cells treated whit $\mathrm{HCl}(2 \mathrm{M})$ were immobilized on pistachio whit $10 \mathrm{ppb}$ and $20 \mathrm{ppb}$ aflatoxin $\mathrm{B} 1$ : for $12 \mathrm{hr}$ at $25{ }^{\circ} \mathrm{C}$

ELISA results done by Hasakard, El-Nezami, Kakkaanpaa, Salminen, Ahokas (2001) showed that acidic treatment may cause intercellular binding, which might be a reason for the higher observed binding percent under acidic conditions versus other treatments. The better binding ability of the physically and chemically modified cells against the viable cells indicates a physical nature of binding rather than a metabolic process. Chromatographic analysis by MadrigalSantilla'n, Madrigal-Bujaidar, Ma'rquez-Ma'rquez, Reyes (2006) showed similar densitograms between the $\mathrm{AFB}_{1}$ absorbed by yeast and an $\mathrm{AFB}_{1}$ standard. Additionally, absorption caused no structural changes in mycotoxin.

According to Bueno, Casale, Pizzplitto, Salvano, Oliver (2007), a physical absorption model is suggested for the binding of $\mathrm{AFB}_{1}$ to Saccharomyces cerevisiae. The model allows the evaluation of two parameters: the number of binding sites per microorganism (M) and the reaction equilibrium constant $\left(\mathrm{K}_{\mathrm{eq}}\right)$, both of which are valuable for estimating the adsorption effectiveness of a particular microorganism. They indicated that the $\mathrm{M}$ amount for yeast was $1 \times 10^{11}$ 
sites/microorganism, and thus, we can consider it as a factor for $\mathrm{AFB}_{1}$ binding to yeast. The nature of the cell wall components involved in mycotoxin binding is still not clear. Carbohydraterich mannoproteins or glucans may be the likely candidates involved in the binding.

\section{Effect of immobilization on the qualitative characteristics}

\section{of pistachios}

\section{Microstructure evaluation}

Cells immobilized on pistachios were found to be suitable for aflatoxin binding at ambient temperatures. Cell immobilization on pistachio samples was proved by the ability of the immobilized $S$. cerevisiae to perform successive surface binding. Electron microscopy examination (Fig. 7) showed yeast cells immobilized in alginate solution.

\section{Color}

Appearance, particularly color, is one of the first attributes used by consumers for acceptability of a food. The data in Figure 4 represent the color parameters. L, a, and b values, which measure whiteness, redness, and yellowness, were $41.81,13.38$, and 14.98, respectively, for the samples without treatment with yeast (at $\mathrm{t}=0$ ); however, color values did not show any significant changes after coating with alginate and yeast during the exposure time. The appearance of the pistachios was still acceptable.

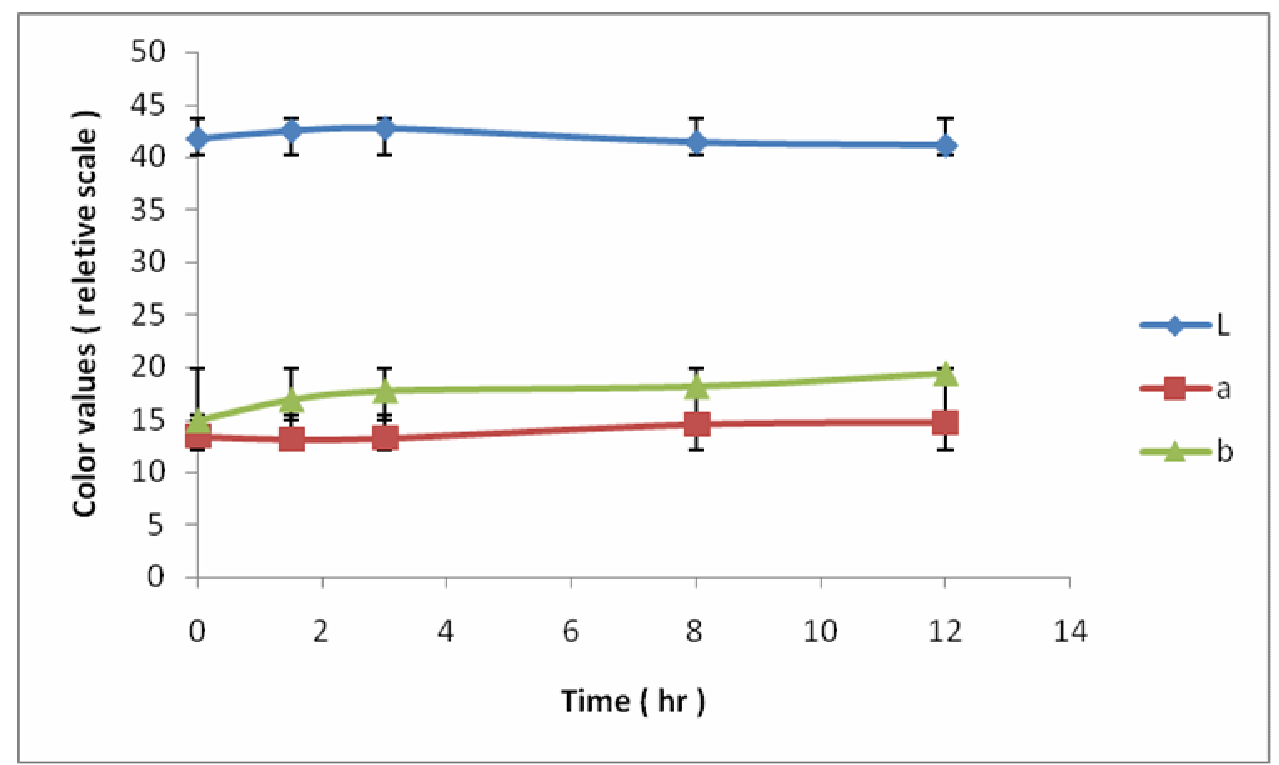

Figure 4. Changes in color values of coated pistachio samples treated with saccharomyces cerevisiae for 12 hour

\section{Peroxide value}

The peroxide value represents the quality of pistachios, including fat content and freshness; however, peroxide values in Figure 5 did not show any significant changes after immobilization of yeast on pistachio samples during the experiment.

\section{Texture}

In this research, the immobilization of $S$. cerevisiae did not affect coated pistachios and did not cause any changes in texture. Figure 6 represents a punch experiment of pistachio samples before and after coating. Statistical analysis shows an analogous result for the pistachio samples. Hardness of the pistachio samples was $22.5 \%$ and $21.5 \%$ before and after the alginate coating, respectively. Minute differences between them may be due to variance in moisture after the alginate coating. 
Rahaie, S. et al.

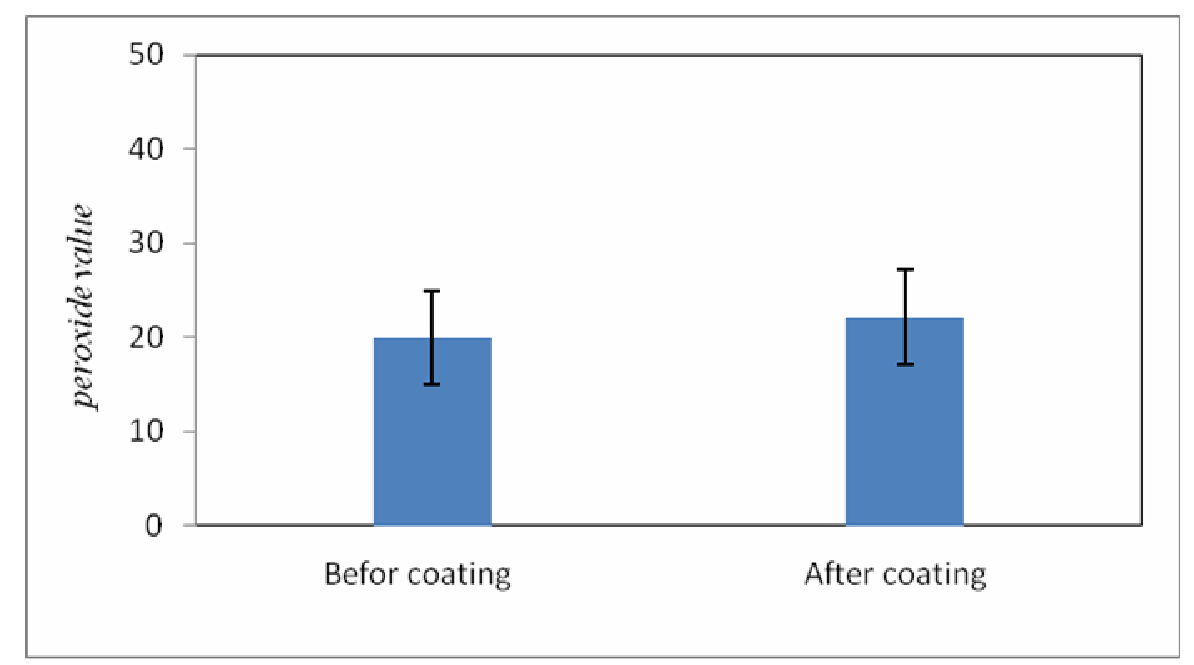

Figure 5. Peroxide values of pistachio samples before and after immobilization

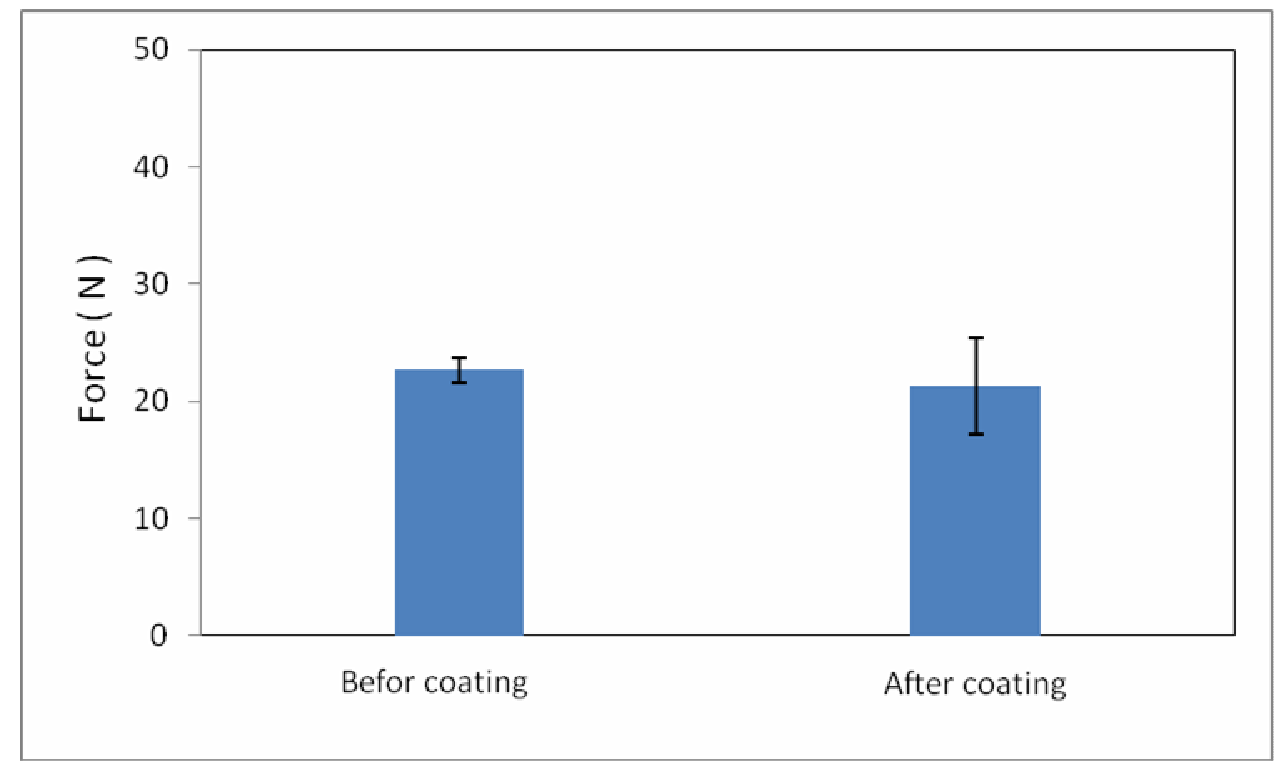

Figure 6. Required force for Punch experiment of pistachio samples before and after coating
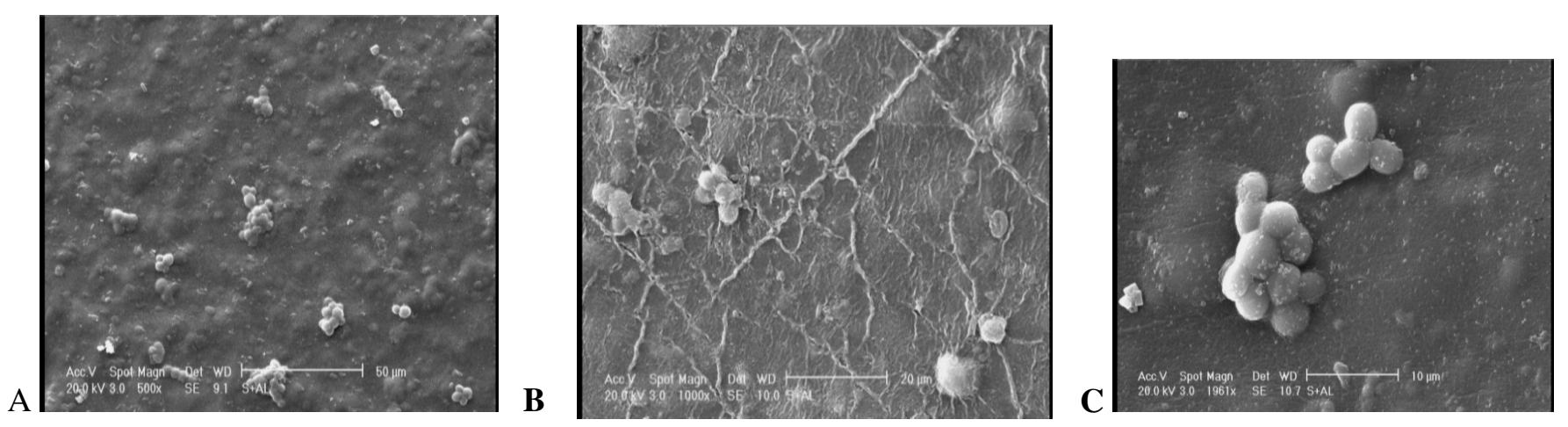

Figure 7. Scanning electron microscopy of S. cerevisiae ATCC 9763 cells Immobilized on the surface of pistachio. (A: 500 X, B: 1000 X, C: 2000 X) 


\section{CONCLUSION}

Results indicated that:

1) $\mathrm{AFB}_{1}$ binding to yeast was a rapid process.

2) The amount of $\mathrm{AFB}_{1}$ removed was related to toxin concentration.

3) Similar results were obtained with viable and nonviable (heat-treated and acid treated) yeast, confirming that the viability of the yeast was not a significant factor.

Results also showed that yeast immobilization on aflatoxincontaminated pistachios for toxin reduction had no effect on the qualitative characteristics of the nut, such as color, texture, and peroxide value. Furthermore, it was shown that the studied yeast strains were more efficient than the yeast strains in indigenous fermented foods, as seen by Shetty and Jesperson (2006).

Systematic studies with the intact cells and isolated cell walls are still needed to understand the chemistry of binding. Although the cell surface physical binding in general is a similar rapid phenomenon, kinetics of binding may differ. Stability of the yeast-aflatoxin complex under the harsh conditions of the gut has yet to be investigated; however, further studies are needed to identify the mechanism of binding, to identify the cell surface binding structures, and to study the constancy of the compound under physical-chemical conditions comparable to the conditions in the gastro-intestinal tract.

\section{ACKNOWLEDGMENT}

We would like to express our thanks to the "Iran Industrial Research and Standards Institution" and to "Research Council of the University of Tehran" for their financial assistance for this study.

\section{REFERENCES}

1. Abdulkadar, A.H.W.; Al-Ali, A.; Al-Jedah, J. (2000). Aflatoxin contamination in edible nuts imported in Qatar. Food Control, 11, 157160 .
2. Aghamohammadi, M.; Hashemi, J.; Asadi Kram, G.R.; Alizadeh, N. (2007). Enhanced synchronous spectrofluorimetric determination of aflatoxin B1 in pistachio samples using multivariate analysis. Anal. Chim. Acta, 582, 288-294.

3. AOCS (1993). Official methods and recommended practices of the American oil chemists' society ( $4^{\text {th }}$ ed.). Champaign, IL: AOCS Press.

4. Beta, A.; Lasztity, R. (1999). Detoxification of mycotoxin contaminated food and feed by microorganism. Trends in Food Science and Technology, 10, 223-228.

5. Bueno, D.J.; Casale, C.H.; Pizzplitto, R.P.; Salvano, M.A.; Oliver, G. (2007). Physical adsorption of aflatoxin B1 by Lactic acid bacteria and Saccharomayces cerevisiae: A theoretical model. J. Food Prot., 70 (9), 2148-2154.

6. Calvo, A.M. (2005). Mycotoxins. In Da browski, W. M., \& Sikorski, Z.E, Toxins in food, 219-240, London, CRC PRESS.

7. Celyk, K.; Denyl, M.; Savas, T. (2003) Reduction of aflatoxin $B_{1}$ by using baker yeast (Saccharomyces cerevisiae) in growing broiler chicks diet. R. Bras. Zootec., 23 (3), 615-619.

8. Cheraghali, A.M.; Yazdanpanah, H.; Doraki, N.; Abouhossain, G.; Hassibi, M.; Ali-abadi, S. (2006). Incidence of aflatoxins in Iran pistachio nuts. Food Chem. Toxicol., 45, 812-816.

9. Ghanem, I.; Orfi, M.; Shamma, M. (2008). Effect of gamma radiation on the inactivation of aflatoxin $\mathrm{B}_{1}$ in food and feed crops. Braz. J. Microbiol., 38, 787-791.

10. Hadavi, E. (2005). Several physical properties of aflatoxin-contaminated pistachio nuts: Application of BGY fluorescence for separation of aflatoxin-contaminated nuts. Food Addit. Contam., 22(11), 1144-1153.

11. Hasakard, C.A.; El-Nezami, H.S.; Kakkaanpaa, P.E.; Salminen, S.; Ahokas, J.T. (2001). Surface binding of aflatoxin B1 by Lactic acid bacteria. Appl. Environ. Microbiol., 3086-3091.

12. Janssen, M.M.T.; Put, H.M.C.; Nout, M.J.R. (1997). Natural toxins. In: Vries, J.D. (ed) Food Safety and Toxicity, CRC PRESS, London, England, p. 16-47.

13. Kourkoutas, Y.; Kanellaki, M.; Koutinas, A.A. (2006). Apple pieces as immobilization support of various microorganisms, LWT, 39, 980-986.

14. Madrigal-Santilla'n, E.; Madrigal-Bujaidar, E.; Ma'rquez-Ma'́rquez, R.; Reyes. A. (2006). Antigenotoxic effect of Saccharomyces cerevisiae on the damage produced in mice fed with aflatoxin B1 contaminated corn. Food Chem. Toxicol., 44, 2058-2063.

15. Prado, G.; Pinheiro de Carvalho, E.; Silva Oliviera, M.; Cruz Madeira, J.G.; Morais, V. D.; Correa, R.F.; Cardoso, V.N.; Soares, T.V.; Moreira da Silva, J.F.; Pereira Goncalves, R.C. (2003). Effect of gamma irradiation on the inactivation of aflatoxin $\mathrm{B}_{1}$ and fungal flora in peanut. Braz. J. Microbiol., 34, 138-140.

16. Razavi, S.M.A.; Taghizadeh, M. (2007). The specific heat of pistachio nuts as affected by moisture content, temperature, and variety. J. Food Process Eng., 79, 158-168. 
Rahaie, S. et al.

17. Sheibani, A.; Ghaziaskar. H.S. (In press). Pressurized fluid extraction for quantitative recovery of aflatoxins B1 and B2 from pistachio. Food Control (In press).

18. Shetty, P.H.; Jespersen, L. (2006). Saccharomyces cervisiae and lactic acid bacteria as potential mycotoxin decontaminating agents. Trends in
Food Science and Technology, 17, 48-55.

19. Shetty, P.H.; Hald, B.; Jespersen, L. (2006). Surface binding of aflatoxin B1 by saccharomyces cervisiae strains with potential decontaminating abilities in indigenous fermented foods. Int. J. Food Microbiol., 113 (1), 41-46. 